\title{
LARINGITIS OBSTRUCTIVAS
}

\section{Drs, OSCAR ILLANES, WERNER BUSTAMANTE, JOSE LEGARRETA y MARCOS KIRBERG}

Cátedra de Pediatria dis Prof. A. Ariztia.

(Servicio Infectioso Hlospital "I, tis Calvo Mackenta")

con la colaboración dil Dr. Humberto Cooper, Jefe del Depto de Otorrinolaringologia.

En el presente trabajo daremos a conocer en forma resumida la experiencia reunida en el Servicio de Infecciosos del Hospital de Niños "Luis Calvo Mackenna", con las laringitis obstructivas $\mathrm{y}$ no obstructivas, hospitalizadas durante los meses de Enero a Agosto de 1958, y muy en especial a las de etiología sarampionosa, ya que durante ese año Santiago se vió azotado por una epidemia de sarampión que se caracterizó por sus complicaciones de tipo respiratorio.

Con el fin de evitar confusiones, hemos creido de interés definir en primer lugar los térninos que usaremos en nuestra exposición. Para empezar, estimamos que el vocablo laringitis en estos casos es inapropiado, ya que hay siempre compromiso, en mayor o menor extensión, de las vías respiratcrias. La usaremos para poder referirnos en mejor forma al síntoma principal de la obstrucción respiratoria alta y podernos encuadrar dentro del tema. Hablamos de laringitis no obstructiva, cuando existe afonia, disfonia, tos crupal; sin dificultad en el paso del aire. Laringitis obstructiva, cuando, además de Ios sinto-

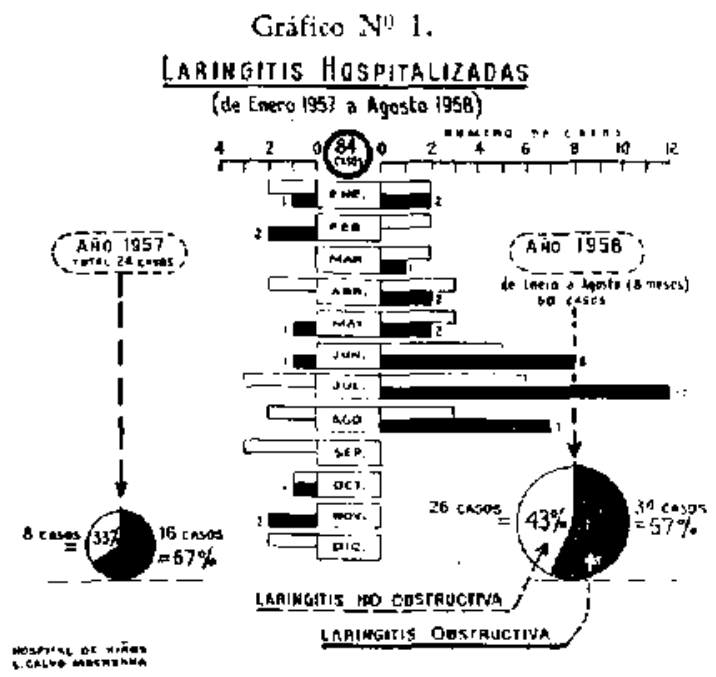

mas anteriores, existe dificultad respiratoria de tipo laríngeo, caracterizado por estridor, retracción supra e infra esternal y supra e infra clavicular. En cuanto al perícdo del sarampión en que aparece la complicación laringea, hemas preferido usar el término de "fase aguda" para referirnos al período eruptivo, y "post-sa. rampión" cuando la complicación aparece clinicamente después del periodo eruptivo.

\section{Laringitis hospitalizadas}

Entre Enero y Agosto de 1958, se hos: pitalizaron en el Servicio de Infecciosos 60 casos de laringitis, siendo 26 de ellas $(43 \%)$ de tipo no obstructivas y $34(57 \%)$ de tipo obstructivo, llamando la atención el gran aumento de hospitalizados durante los meses de Junio, Julio y Agosto, época en que el brote epidémico de sarampión alcanzó su mayor magnitud.

En el gráfico 1 hacemos un análisis de las laringitis hospitalizadas durante el año 1957 y 1958 (Enero - Agosto), donde puede observarse el gran aumento experimentado en los primeros ocho meses del año 1958 (60 casos), comparados con los 24 casos hospitalizados en el año 1957.

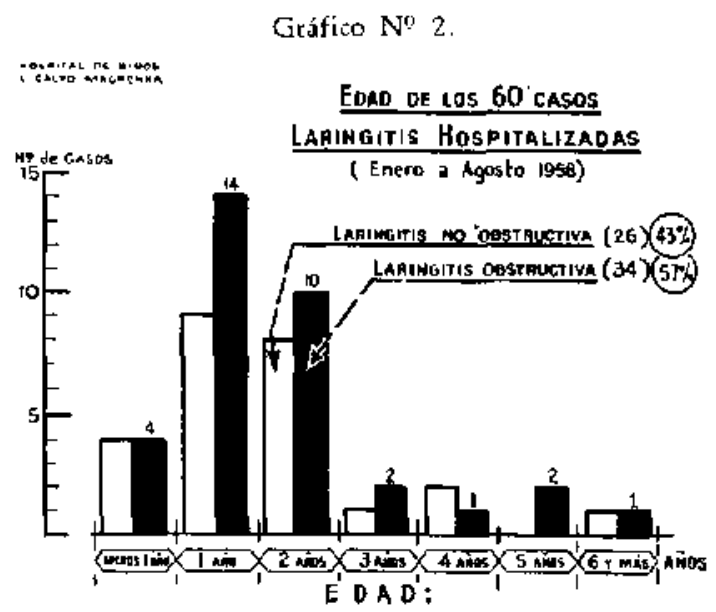


Edad

El mayor número de laringitis obstructivas las observamos durante el año de edad, con 14 casos; después de los 2 años se observa una franca disminución. Gráfico 2.

\section{Etiologia}

En cuanto a la etiología, hubo 46 casos que fueron de origen sarampionosas, de las cuales 26 tuvieron el carácter obstructivo y 20 no obstructivo. Los 14 restantes fueron laringitis no sarampionosas, 12 de ellas del tipo catarral. Cuadro 1.

CJADRO NO 1

ETIOLOGIA DE LAS LARINGITIS

\begin{tabular}{|c|c|c|c|}
\hline \multicolumn{2}{|l|}{ 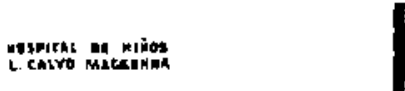 } & $\begin{array}{l}\text { AÑo } \\
1957\end{array}$ & $\begin{array}{c}\text { (ENE - AGO.) } \\
1958\end{array}$ \\
\hline \multirow{3}{*}{$\begin{array}{c}\text { NO } \\
\text { SARAMPIONOSA }\end{array}$} & DESTRUCTIVA & 3 & $B$ \\
\hline & No OBSTRUCT. & 12 & 6 \\
\hline & T OTAL & 15 & 14 \\
\hline \multirow{3}{*}{ SARAMPIONOSA } & OBSTRUCTIVA & 1 & 26 \\
\hline & NO DBSTRUCT. & 8 & 20 \\
\hline & TOTAL & 9 & 46 \\
\hline
\end{tabular}

Laringitis sarampionosas

En nuestro material encontramos un total de 34 casos de laringitis obstructivas hospitalizadas, de las cuales 8 fueron catalogadas como no sarampionosas. Entre estos 26 casos solamente 7 presentaron el accidente obstructivo durante la fase aguda del sarampión y 19 en el período postsarampión.

En 12 casos la evolución seguida fué de carácter benigno y en 14 tuvo caracteres graves, acusando un total de 3 fallecidos en el grupo de las laringitis obstructivas sarampionosas y ninguno entre las del tipo no obstructivas. Hasta la fecha hemos tenido un $8.8 \%$ de mortalidad si Ia relacionamos con los 34 casos de laringitis obstructivas hospitalizadas y en $11.5 \%$ si nos referimos exclusivamente a las obstructivas de etiología sarampionosa. Cuadro 2.
CUADRO Nọ 2

coscitm of mitios

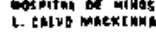

LAaIngITIS SaRAMpIONOSA

Epoca de aparicion y EnF. Asoctadas

Emé́o a Agosto 1950

\begin{tabular}{|c|c|c|c|}
\hline \multirow{2}{*}{$\begin{array}{l}\text { TIPO LARINGIIIS } \\
\text { EHF. ASOCIADAS }\end{array}$} & \multicolumn{3}{|c|}{ PEAIODO DEL. SAAAMP. } \\
\hline & Fase Aguda & PDST SNAMMP. & TOTAL \\
\hline OBSTRUCTIVA & 7 & 19 & 26 \\
\hline BRONLONEUMOMIA & 5 & 5 & 10 \\
\hline NO OBSTRUCTIVA & 4 & 16 & 20 \\
\hline BRDMCONEUMONIA & 0 & 3 & 3 \\
\hline
\end{tabular}

\section{Complicaciones}

La complicación más frecuente que se ascció a la laringitis sarampinosa fué la brcnconeumonia. En el Cuadro 3 podemos cbservar que ésta afectó con mayor proporción $(38.5 \%)$ al grupo obstructivo sarampionoso, ya que en un total de $26 \mathrm{ca}$ sos esta complicación apareció en 10 de ellos. La evolución clínica, confirmada pesteriormente en la necropsia, demuestra que de los 3 casos fallecidos ninguno fué por su obstrucción laríngea, sino que por su extensa y grave bronconeumonia.

\section{CUADRO Ne 3}

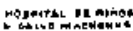

LaRINGITIS OBSTRUC,TIYAS HOSPITALIZADAS

(Erero a Agosto de 1958)

\begin{tabular}{|c|c|c|c|c|c|c|c|}
\hline & $\left\{\begin{array}{c}\text { No } \\
\text { oe } \\
\text { CASOS }\end{array}\right.$ & $\begin{array}{l}\text { Solakn- } \\
\text { Prowoses }\end{array}$ & 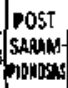 & $\begin{array}{l}\text { BENMG } \\
\text { NAS }\end{array}$ & GAMES & $\begin{array}{l}\text { FALLE. } \\
\text { CIDES }\end{array}$ & $\%$ \\
\hline $\begin{array}{l}\text { LARINGITIS } \\
\text { SARAM WIONASAS }\end{array}$ & 26 & 7 & 19 & 12 & 14 & 3 & 11,5 \\
\hline $\begin{array}{l}\text { LARINGITIS } \\
\text { NO SARAAPFONOSAS }\end{array}$ & 8 & & & 6 & 2 & 0 & D \\
\hline TOTALES & 34. & & - & 18 & 16 & 3 & $B, 6$ \\
\hline
\end{tabular}

Estudio laríngeo

El estudio laríngeo figura como uno de los exámenes de rutina a que se somete un enfermo de esta naturaleza. Se lleva a efecto en las primeras horas de su ingreso. Para este objeto se cuenta con la 
intima y estrecha colaboración del Servicio de Otorrino., quién realiza la Jaringoscopia directa. Además se aprovecha este examen, cuando es necesario, para realizar la aspiración de mucosidades y la tona de muestra para exámenes bacteriológicos.

En el material que presentamos se hizo cste estudio con especial dedicación por parte del Dr. Humberto Cooper, quien tuvo a su cargo casi todos los exámenes y controles laríngeos. De las 34 laringitis obstructivas hospitalizadas, solamente en $24\left(70,6^{\prime} ;\right)$ pudo hacerse este examen. Entre los hallazgos más importantes figura de preferencia la congestión y edema de la mucosa. En 6 casos se observó un exudado de tipo membranoso muy dificil de diferenciar con el tipo difterico y cuyo examen bacteriológico fué negativo para el bacilo de Loeffler. Cuadro 4.

\section{CUADRO NQ 4}

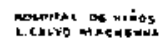

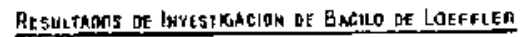
EN LAS LaAingitis OGSTAuttivas HOSP htalizadas (Enero a Agosto de 1958)

\begin{tabular}{|c|c|c|c|c|}
\hline & \multirow{2}{*}{\multicolumn{2}{|c|}{$\underset{E X O M}{\operatorname{CON}}$}} & \multicolumn{2}{|c|}{ LOEFFLEA } \\
\hline & & & Dositivo & HEGATIVO \\
\hline $\begin{array}{l}\text { EXAMEH OE } \\
\text { SECRECION LAAINGEA }\end{array}$ & 24 & 10 & 0 & 24 \\
\hline $\begin{array}{l}\text { EXAMEH DE SECFECION } \\
\text { FARINGEA }\end{array}$ & 30 & 4 & 3 & 27 \\
\hline
\end{tabular}

Junto al estudio bacteriológico de la secreción laríngea, se tomó también muestra de la secreción faríngea y nasal. En 24 casos de laringitis obstructivas en quienes se estudió la presencia del bacilo de foeffler, este dió resultados negativos. Los 3 casos positivos que se encontraron, correspondian a las muestras de secreción faríngea y nasal.

\section{TRATAMIENTO}

Nuestro plan de tratamiento para las laringitis obstructivas estaba orientado en primer lugar a combatir y aliviar el síndrome obstructivo. Para este objeto usamo nuestros equipos de croupette, los cuales fueron después insuficientes, remediándose esta situación con la llegada oportuna de los nuevos equipos propor- cionados por el Servicio Nacional de Salud. Dentro de la croupette el niño recibía oxigeno, vapor de agua y detergentes para fluidicar las secreciones. Cada vez que se estimaba necesario, se hacian las aspi raciones para despejar las vías respirato. rias mediante las aspiradoras eléctricas portátiles del Servicio de Infecciosos.

Debemos llamar la atención que no todas las laringitis obstructivas hospitalizadas estuvieron en la croupette. Solamente 20 de ellas, entre los 34 casos reunidos, permanecieron más de 12 horas, con un promedio de 3.5 dias. El resto estaba constantemente bajo vigilancia estricta, o bien estuvieron pocas horas en croupette, ya que según nuestra organización interna hospitalaria, estos niños ingresaban primero por la Policlinica al Servicio de Media Hospitalización, donde recibian sus primeras atenciones y cuidados.

Como segunda medida dentro de nuestro tratamiento fué la sedación del enfermo. Con este fin preferimos desde un comienzo el uso del "Calcibronat", que por sus caracteristicas farmacológicas y la oxperiencia reunida en años anteriores nos aseguraba un recurso de gran utilidad. Lo usamos a razón de 2.5 cc endovenoso para los menores de un año, y 5 cc para los mayores del año, dosis que repetíamos. de acuerdo con la evolución clínica, cada 6. 12 ó 24 horas. Este medicamento fué aplicado en 25 casos y en general no más de 2 a 3 días. No observamos inconvenientes, por el contrario, nos permitió en la gran mayoría de los casos obtener en forma rápida y oportuna la sedación del enfermo.

Todos nuestros enfermos estuvieron también sometidos a una terapia anti-infecciosa a base de antibióticos, usando en 21 casos la combinación penicilina/estreptomicina, por via intramuscular. En el resto se usó diferentes combinaciones y además tetraciclinas en las dosis habituales por vía oral o intramuscular. Sin embargo en los casos más graves y complicados se usó por vía endovenosa la "Sigmamicina", con Ia cual obtuvimos resultados muy alentadores, pero muy pocos para poder sacar alguna conclusión.

En 5 casos usamos los corticoides, medicación que en general la suspendimos por no considerarla indicada.

Combinado con el tratamiento anterior descrito, en 11 casos se aplicó la antitoxina diftérica, especialmente cuando eI 
cuadro clínico hacía sospechar una posible difteria, o bien el examen laríngeo demostraba un exudado difícil de diferenciar con el de tipo diftérico.

Muy pocos de nuestros niños llegaron a la traqueotomía. Tuvimos 4 casos en un total de 34 laringitis obstructivas $(11.8 \%)$; falleciendo 1, al presentar una complicación bronconeumónica grave. En general se trató de ser conservador en la indicación de la traqueotomía debido a que el uso oportuno de la croupette, junto al tratamiento ya mencionado y la atención de enfermería con personal entrenado, permitieron en la gran mayoria de los casos una adecuada recuperación. Tenemos el convencimiento que la terapia así planeada evitó en muchas ocasiones una traqueotomía. No obstante estuvo indicada en en aquellos enfermos con dificultad intensa de la respiración, manifestada por cianosis, sin recuperación a pesar de estar dentro de la croupette y con tratamiento oportuno. También la indicamos en los enfermos que estaban en croupette por obstrucción laríngea prolongada 12-24 horas, sin registrar disminución de su sintomatologia y ante el agotamiento muscular.

En cuanto a las complicaciones posttraqueotomía observadas, estas fueron en especial la formación de secreción espesa y de costras, que dieron lugar a atelectasia y enfisema compensatorio. Estas atelectasias simulan una condensación pulmonar que hemos visto desaparecer con la extracción de costras desde el bronquio en que está ubicado el proceso. La nebulización de vapor de agua y detergentes (Alevaire) por intermedio de la croupette, facilitó la fluidificación de las secreciones espesas $\mathrm{y}$ su aspiración, despejando las vías respiratorias bronquiales.

\section{RESUMEN}

Los autores presentan su experiencia y resultados obtenidos con las laringitis obstructivas hospitalizadas en el Servicio de Infecciosos del Hospital de Niños "Luis Calvo Mackenna" durante los meses de Enero a Agosto de 1958. Durante ese periodo se hospitalizaron 60 casos de laringitis, siendo 26 de ellas de tipo no obstructivas y 34 de carácter obstructivas, Ilamando la atención el gran número de hospitalizados durante los meses de Ju- nio, Julio y Agosto, época en que apareció un brote epidémico de sarampión.

En cuanto a su etiología, demuestran que 46 casos fueron de origen sarampiopionosas, de las cuales 26 tuvieron el carácter obstructivo y 20 no obstructivo. Los 14 restantes fueron catalogados como laringitis no sarampionosas, siendo 12 de ellas de tipo catarral.

Las laringitis tuvieron su mayor frecuencia entre los 12 y 24 meses de edad, siendo mucho menos frecuente antes del año y después de $\operatorname{los} 2$ años.

A1 analizar las laringitis obstructivas sarampionosas destacan el hecho que dentro del grupo de 26 casos hospitalizados Ia gran mayoria presentan este accidente en el período post-sarampión, 19 casos; 7 se registran durante la fase eruptiva de es. ta enfermedad. La evolución seguida fué de carácter grave en 14 de ellas y 12 de tipo benigna, acusando un total de 3 fallecidos, to cual representa una mortalidad del $11.5^{r}$; entre las laringitis obstructivas sarampionosas. La complicación más frecue-ite encontrada junto al cuadro obstiucti vo fué la bronconeumonia, observada en 10 casos.

Con respecto al estudio laringoscópico mencionan no haber tenido tropiezos $\mathrm{ni}$ accidentes con la laringoscopia directa, y que este examen no ofrece mayores dificultades si es realizado por personal competente. En el $70.6 \%$ de las laringitis obstructivas hosvitalizadas se practicó una laringoscopia directa al ingreso, encontrando de preferencia congestión $\mathrm{y}$ edema. En 6 casos se observó un exudado de tipo membranoso difícil de diferenciar con los de tipo diftérico, cuyo examen bacteriológico fué negativo para el bacilo de Loeffler

Como tratamiento usaron la croupette, lo cual facilitó enormemente el tratamiento a base de oxigeno $\mathrm{y}$ humedad. Entre los antibióticos usaron la combinación penicilina-estrento.. o bien las tetraciclinas de amplio espectro. Entre la medicación sedante usaron de oreferencia el calcibronat, de cuvos resultados se muestran satisfechos. Sólo en 5 casos usaron corticoides, siendo abandonado su uso por no considerarlos indicados. La traquetomía fué realizada en 4 casos, falleciendo uno de ellos por complicación bronconeumónica. 